\title{
Determinants of growth differentiation factor 15 in patients with stable and acute coronary artery disease. A prospective observational study
}

Serdar Farhan ${ }^{1 *}$, Matthias K. Freynhofer ${ }^{1}$, Ivan Brozovic ${ }^{1}$, Veronika Bruno ${ }^{2}$, Birgit Vogel ${ }^{1}$, loannis Tentzeris ${ }^{1}$, Sabina Baumgartner-Parzer ${ }^{3}$, Kurt Huber ${ }^{1}$ and Alexandra Kautzky-Willer ${ }^{3}$

\begin{abstract}
Background: Growth differentiation factor 15 (GDF-15) is a member of the transforming growth factor $\beta$ family and has been associated with inflammation, cancer, aging, diabetes mellitus (DM) and atherosclerosis. Determinants of GDF-15 have been investigated in several conditions. We aimed to investigate determinants of GDF-15 plasma levels in patients with angiographically proven coronary artery disease (CAD).

Methods: Four hundred and seventy three consecutive patients with CAD were investigated between May 2009 and February 2011. Patients were separated into those with stable CAD (SCAD) and with ST-elevation and non-ST-elevation myocardial infarction (STEMI and NSTEMI). Blood samples for determination of GDF-15 were obtained before coronary angiography. Determinant of GDF-15 levels were analyzed by logistic regression analysis in unadjusted and adjusted models. Study endpoints were cardiovascular death (CV-death), myocardial infarction, unstable angina, unplanned revascularization, stent thrombosis and stroke assessed at a mean follow-up of 188 (177.2-243) days.

Results: Overall median and (25-27th percentile) GDF-15 level was 1212.8 pg/ml (833.2-1957 pg/ml). GDF-15 was significantly higher in STEMI compared to SCAD and NSTEMI groups $(P<0.0001)$. In a multivariate regression analysis advanced age, DM, acute hyperglycemia (AHG), CRP and chronic kidney disease (CKD) were independent predictors of elevated GDF-15 levels ( $P<0.05)$. Receiver operating curve analysis of GDF-15 for prediction of $C V$-death showed an area under the curve of 0.852 with a confidence interval of $0.745-0.960, P<0.0001$. The estimated cut-off was $2094.6 \mathrm{pg} / \mathrm{ml}$ with a sensitivity of $76 \%$ and specificity of $80 \%$.

Conclusion: In patients with CAD undergoing PCI with stent implantation, GDF-15 is determined by advanced age, acute and chronic hyperglycemia, inflammation and CKD. GDF-15 is a valuable predictor of CV-death in a population of CAD patients after PCI.
\end{abstract}

Keywords: Growth differentiation factor 15, Acute coronary syndrome, Coronary artery disease, Diabetes mellitus, Acute hyperglycemia

\section{Background}

Growth differentiation factor 15 (GDF-15) is a member of the transforming growth factor family [1]. GDF-15

\footnotetext{
*Correspondence: farhanserdar@gmail.com

1 3rd Department of Medicine, Cardiology, Wilhelminen Hospital,

Montleartstrasse 37, A-1160 Vienna, Austria

Full list of author information is available at the end of the article
}

has been described in various conditions [2-4]. GDF-15 has been introduced as a prognostic marker for patients with coronary artery disease (CAD) especially in the case of acute non-ST-elevation myocardial infarction (NSTEMI) [5-7]. Additionally GDF-15 has been linked to hyperglycemia and diabetes mellitus (DM) [4, 8]. GDF-15 was investigated also as a predictor of future insulin resistance and impaired glucose control in obese 
non-diabetic subjects [9]. Furthermore, GDF-15 was linked to impaired fasting glucose [8]. Additionally GDF15 predicted worsening albuminuria in patients with DM [3].

Few data are available on determinants of GDF-15 in patients with CAD. Therefore we aimed to investigate GDF-15 in patients with CAD undergoing percutaneous coronary intervention (PCI) with stent implantation.

\section{Methods}

In total 473 consecutive patients from the WIlhelminen hospital Monitoring of Antiplatelet Activity (WILMAA)registry between May 2009 and February 2011 were included in this prospective observational investigation [10]. Briefly, consecutive patients, with percutanous coronary intervention (PCI) and coronary stenting due to stable coronary artery disease (SCAD) with positive ischemia testing (treadmill examination, dobutamine stress echocardiography or single-photon-emission computed tomography) or acute coronary syndrome (ACS), aged $>18$ years were eligible for inclusion in the present study. ACS was diagnosed according to the guidelines of the European Society of Cardiology (ESC) [11, 12]. Implantation of drug eluting or bare metal stents, and the use of accompanying antithrombotic regimens were based on the decision of the treating interventionist. The city of Vienna ethic committee approved the study and all patients gave their informed consent.

Patients were divided according their presentation into those with SCAD as well as ST-elevation myocardial infarction (STEMI) or NSTEMI.

Definitions Acute hyperglycemia (AHG) was defined as glucose concentration of $\geq 140 \mathrm{mg} / \mathrm{dl}$ in absence of DM in patients admitted with ACS [13], chronic kidney disease (CKD) was defined as an estimated glomerular filtration rate (eGFR) of $<60 \mathrm{ml} / \mathrm{min}$ at admission [14]. DM was defined as history of elevated glucose concentrations treated by dietary control or using glucose-lowering drugs. History of congestive heart failure (CHF) was defined according to the European society of cardiology guidelines (ESC) [15].

\section{Endpoint definition}

According the recommendation of the Academic Research Consortium regarding stent trials [16], the following endpoints were investigated: (1) cardiovascular death according to the TIMI-definition (http://www.timi. org), as well as any death that could not be attributed to non-cardiovascular reasons (2) nonfatal myocardial infarction according to the TIMI-definition (http://www. timi.org) as well as (3) any unplanned revascularization. Additionally (4) definite and probable stent thrombosis (ST) according to the academic research consortium definition [16], (5) unstable angina defined as ischemic symptoms without elevation of troponin I above the upper limit of normal and (6) transient ischemic attack (TIA) [17] or stroke, defined as cerebral infarction were recorded. Data were collected prospectively and entered into a database. Follow-up information was obtained by contacting patients after 6 months ( \pm 2 months). Source documents of all possible events were collected.

\section{Laboratory parameters}

Blood samples for glucose, high sensitive C-reactive protein (CRP) and creatinine were obtained at hospital admission and high- and low-density lipoprotein (HDL and LDL) cholesterol and triglycerides were collected at the first day after admission in fasting condition. A certified clinical laboratory at our hospital performed the measurement of that laboratory parameter. Blood samples for GDF-15 were collected before coronary angiography. Blood samples for detection of GDF-15 were centrifuged immediately after collection and were stored at $-80{ }^{\circ} \mathrm{C}$ until measurement. GDF- 15 plasma concentrations were measured using a quantitative sandwich ELISA kit (Quantikine ELISA, R\&D Systems) with interand intra-assay $\mathrm{CVs}$ of $<6$ and $2.8 \%$, respectively.

\section{Statistical analysis}

Continuous data are expressed as proportions and continuous data as mean \pm standard error of the mean. Categorical variables were compared by Chi square test, while analysis of variance (ANOVA) for continuous variables. Determinates of GDF-15 levels were tested using a univariate binary logistic regression analysis. All variables, which were tested significant in the univariate model, were inserted in a multivariate binary logistic regression model with inclusion method. Results of binary logistic regression analysis were presented as odds ratio (OR) and $95 \%$ confidence interval (CI). Receiver operating characteristic (ROC) analysis was performed to determine whether GDF-15 plasma levels predict death and ischemic endpoints. All statistical tests were 2 -sided and statistical significance was accepted if the $\mathrm{p}$ value was $<0.05$. All statistical analyses were performed using Software Package Social Sciences (IBM, SPSS).

\section{Results}

The median (25-27th percentile) of GDF-15 levels was $1212.8 \mathrm{pg} / \mathrm{ml}(833.2-1957 \mathrm{pg} / \mathrm{ml})$ in our study population. Patient's demographic and clinical presentation data are depicted in Table 1. Patients with STEMI were significantly more smokers than those with SCAD and NSTEMI patients. On the other side patients with SCAD had higher cardiovascular risk profile in terms of significantly higher rates of hyperlipidemia, lower 
Table 1 Baseline and demographic parameters

\begin{tabular}{|c|c|c|c|c|}
\hline Variable & $\operatorname{SCAD}(n=189)$ & STEMI $(n=121)$ & NSTEMI $(n=163)$ & P value \\
\hline Age & $65.2 \pm 0.786$ & $61.9 \pm 1.34$ & $64.9 \pm 1.05$ & 0.067 \\
\hline Age $>75(\%)$ & $41(21.7)$ & $29(24)$ & $45(27.6)$ & 0.433 \\
\hline Female gender (\%) & $55(29.1)$ & $41(33.9)$ & $54(33.1)$ & 0.60 \\
\hline Hypertension (\%) & $170(90)$ & $98(81)$ & $139(85.3)$ & 0.058 \\
\hline Hyperlipidemia (\%) & $160(85.1)$ & $83(68.6)$ & $129(79.1)$ & 0.002 \\
\hline Current smoking (\%) & $39(20.6)$ & $44(36.4)$ & $52(31.9)$ & 0.006 \\
\hline DM (\%) & $58(30.9)$ & $28(23.1)$ & $50(30.7)$ & 0.27 \\
\hline Family history of CAD (\%) & $77(41)$ & $45(37.2)$ & $62(38)$ & 0.766 \\
\hline Previous MI (\%) & $63(33.5)$ & $19(15.7)$ & $42(25.8)$ & 0.002 \\
\hline CKD (\%) & $33(17.5)$ & $19(15.7)$ & $30(18.4)$ & 0.83 \\
\hline GDF-15 pg/ml & $1421.1 \pm 74.9$ & $2189.2 \pm 206.7$ & $1695 \pm 114.8$ & $<0.0001$ \\
\hline $\mathrm{BMI}\left(\mathrm{Kg} / \mathrm{m}^{2}\right)$ & $28.51 \pm 0.35$ & $28 \pm 0.43$ & $27.97 \pm 0.35$ & 0.499 \\
\hline e-GFR (ml/min) & $65.27 \pm 0.71$ & $63.65 \pm 1.04$ & $63.57 \pm 1.03$ & 0.31 \\
\hline $\mathrm{CRP}(\mathrm{mg} / \mathrm{dl})$ & $7.83 \pm 2.28$ & $17.42 \pm 3.88$ & $11.05 \pm 2.26$ & 0.062 \\
\hline Cholesterol (mg/dl) & $178.5 \pm 3.66$ & $184.25 \pm 3.89$ & $182.73 \pm 4.16$ & 0.56 \\
\hline HDL-cholesterol (mg/dl) & $46.04 \pm 1.11$ & $41.01 \pm 1.17$ & $43.42 \pm 1.13$ & 0.009 \\
\hline LDL-cholesterol (mg/dl) & $102.34 \pm 2.88$ & $113.58 \pm 3.63$ & $109.88 \pm 3.44$ & 0.051 \\
\hline Triglycerides (mg/dl) & $148.73 \pm 7.29$ & $143.17 \pm 10.81$ & $163.78 \pm 12.52$ & 0.38 \\
\hline Systolic blood pressure $(\mathrm{mmHg})$ & $137.8 \pm 1.5$ & $139.4 \pm 2.5$ & $144.2 \pm 2.4$ & 0.070 \\
\hline Diastolic blood pressure (mmHg) & $80.1 \pm 0.91$ & $81.9 \pm 1.7$ & $81.6 \pm 1.3$ & 0.507 \\
\hline Hospitalization days & $4.84 \pm 0.31$ & $12.94 \pm 1.22$ & $7.32 \pm 0.58$ & $<0.0001$ \\
\hline
\end{tabular}

DM diabetes mellitus, CAD coronary artery disease, CKD chronic kidney disease, GDF-15 growth differentiation factor 15 , BMI body mass index, e-GFR estimated glomerular filtration rate, $C R P$ high sensitive $C$-reactive protein, $H D L$ high-density lipoprotein, $L D L$ low-density lipoprotein

HDL-cholesterol and previous myocardial infarction (Table 1).

Additionally patients with SCAD were trend-wise older than those with ACS (STEMI and NSTEMI patients). Patients with STEMI had significantly more hospitalization days compared to those with SCAD and NSTEMI (Table 1). GDF-15 plasma levels were significantly higher in patients with STEMI compared to SCAD and NSTEMI groups (Fig. 1; Table 1). Patients with ACS (STEMI and NSTEMI together) showed significant higher proportion of GDF-15 plasma levels above $1800 \mathrm{pg} / \mathrm{ml}$ than those with SCAD (68.3 vs. $31.7 \%$ respectively, $\mathrm{P}=0.037$ ). Those patients with GDF-15 plasma levels $>1800 \mathrm{pg} / \mathrm{ml}$ showed higher $\mathrm{CV}$-death rates compared with those patients with GDF- $15<1200$ and $1200-1800$ pg/ml (Fig. 2).

\section{Determinants of elevated GDF-15}

In univariate analysis advanced age (age $>75$ years), ACS on presentation, history of myocardial infarction (MI), current smoking status, elevated BMI $(>25 \mathrm{~kg} /$ $\mathrm{m}^{2}$ ), AHG in those patients with ACS, DM, CKD, CRP and NYHA $\geq 2$ were significant determinants of elevated GDF-15 plasma levels (Table 2). In a multivariate analysis advanced age, DM, AHG, CRP and CKD were independent predictors of elevated GDF-15 levels (Table 2; Fig. 3).

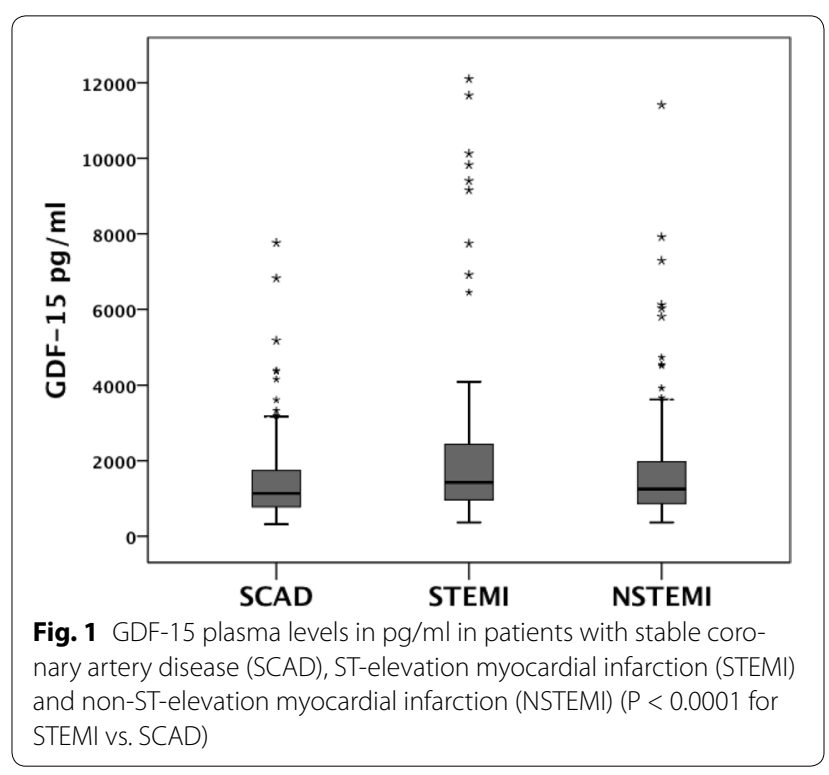

\section{ROC analysis of GDF-15 plasma levels}

GDF-15 was a precise predictor of cardiovascular mortality according to the ROC Analysis [area under the curve (AUC) 0.852, CI 0.745-0.960, $\mathrm{P}<0.0001$ ] (Fig. 4). The best cut-off was $2094.67 \mathrm{pg} / \mathrm{ml}$ with a sensitivity of $76 \%$ and specificity of $80 \%$ (Fig. 4). 


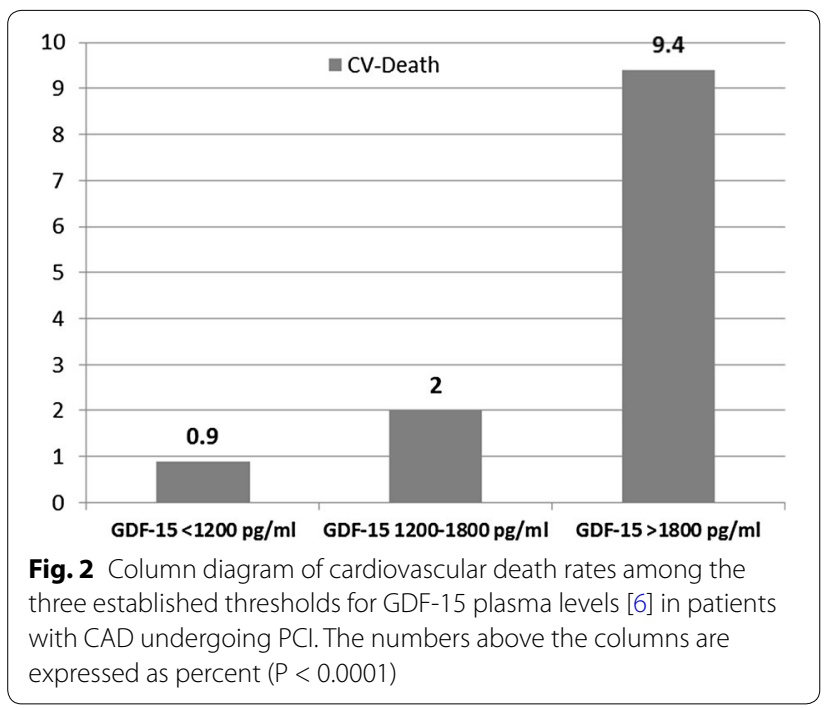

GDF-15 was only weakly predictive of the combined ischemic endpoint (AUC 0.473, CI 0.387-0.560, P 0.044).

\section{Discussion}

The main results of the present study are: first, patients with ACS especially those with STEMI show the highest GDF-15 levels compared to those with SCAD. Second, several factors or conditions are independent determinants of elevated GDF-15 levels in patients with CAD who undergo PCI (advanced age, DM, AHG, inflammation and CKD).

GDF-15 is a member of the transforming growth factor $ß$ family [1]. Under healthy conditions GDF-15 is rarely expressed [5]. In case of oxidative stress and inflammation, GDF-15 expression is up-regulated [18, 19]. Several parameters and conditions have been introduced as inducers of GDF-15 secretion [3, 4, 8, 20-22]. Patients with CAD undergoing bypass surgery are at increased risk to develop acute kidney injury when their pre-operative GDF-15 levels were elevated [23]. In patients with DM, GDF-15 predicts worsening of kidney function measured by albminuria [3]. Several investigations evidenced a relation between GDF-15 and markers of metabolic dysfunction e.g. impaired fasting glucose [8], insulin resistance and glucose metabolism [4], obesity [24], inflammation [1] and finally aging [25]. Our findings correlate with those observations as we found advanced age, DM, obesity $\left(\mathrm{BMI}>25 \mathrm{~kg} / \mathrm{m}^{2}\right)$, CRP and CKD were independent predictors of elevated GDF-15 in patients with CAD who needs PCI. Our investigation extends that knowledge in terms of AHG (Table 2). This is to the best of our knowledge a unique finding of the present study. AHG occurs in nearly $25 \%$ of patients with ACS without history of DM $[26,27]$. AHG has been linked to worse outcome in patients with ACS [28, 29]. AHG remotes ischemic preconditioning in experimental conditions [30]. In an in vitro study, hyperglycemia induced GDF-15 expression, which resulted in umbilical endothelial cell apoptosis [31]. Until today, the reason for elevated glucose levels in the setting of ACS is still matter of debate. Our investigation support the hypothesis that GDF-15 is linked to chronic hyperglycemia in case of DM patients and also to acute deteriorations in glucose metabolism reflected by AHG.

GDF-15 is even found in infracted myocardium as well as atherosclerotic plaque $[5,18,19]$. However, GDF-15 is not a typical marker of myocardial necrosis e.g. troponin $[6,7]$ and could not be used as a marker for detection of acute myocardial necrosis [6, 7]. GDF-15 has been introduced as a prognostic marker in patients with ACS especially those with NSTEMI $[6,7]$. Additionally a sub-study of the ICTUS trial showed a predictive role for GDF-15

Table 2 Unadjusted and adjusted OR for elevated GDF-15 in patients with CAD undergoing PCI

\begin{tabular}{|c|c|c|c|c|}
\hline Variable & Unadjusted OR and 95th Cl & P value & Adjusted OR and 95th $\mathrm{Cl}$ & $P$ value \\
\hline Advanced age (>75 years) & $10.754(6.003-19266)$ & $<0.0001$ & $8.262(3.852-17.722)$ & $<0.0001$ \\
\hline Female gender & $1.414(0.958-2.087)$ & 0.081 & & \\
\hline ACS diagnosis & $1.513(1.045-2.191)$ & 0.028 & $0.912(0.506-1.645)$ & 0.760 \\
\hline AHG in patients with ACS & $3.297(1.567-6.938)$ & 0.002 & $2.815(1.070-7.403)$ & 0.036 \\
\hline $\mathrm{DM}$ & $1.932(1.286-2.903)$ & 0.002 & $2.210(1.222-3.995)$ & 0.009 \\
\hline Previous Ml & $1.606(1.060-2.432)$ & 0.025 & $1.514(0.806-2.844)$ & 0.197 \\
\hline CKD & $12.939(6.071-27.574)$ & $<0.0001$ & $6.846(2.858-16.400)$ & $<0.0001$ \\
\hline NYHA $\geq 2$ at presentation & $1.984(1.050-3.746)$ & 0.035 & $1.647(0.726-3.739)$ & 0.233 \\
\hline Current smoking & $1.930(1.284-2.901)$ & 0.002 & $0.903(0.512-1.595)$ & 0.726 \\
\hline Obesity (BMI > 25 kg/m²) & $1.606(1.050-2.455)$ & 0.029 & $2.184(1.149-4.149)$ & 0.017 \\
\hline Elevated CRP at admission & $1.831(1.206-2.781)$ & 0.005 & $2.380(1.377-4.114)$ & 0.002 \\
\hline
\end{tabular}

OR odds ratio, $C l$ confidence interval, $A C S$ acute coronary syndrome, $A H G$ acute hyperglycemia, $D M$ diabetes mellitus, $M I$ myocardial infarction, $C K D$ chronic kidney disease, NYHA New York Heart Association, BMI body mass index, CRP high sensitive C-reactive protein 


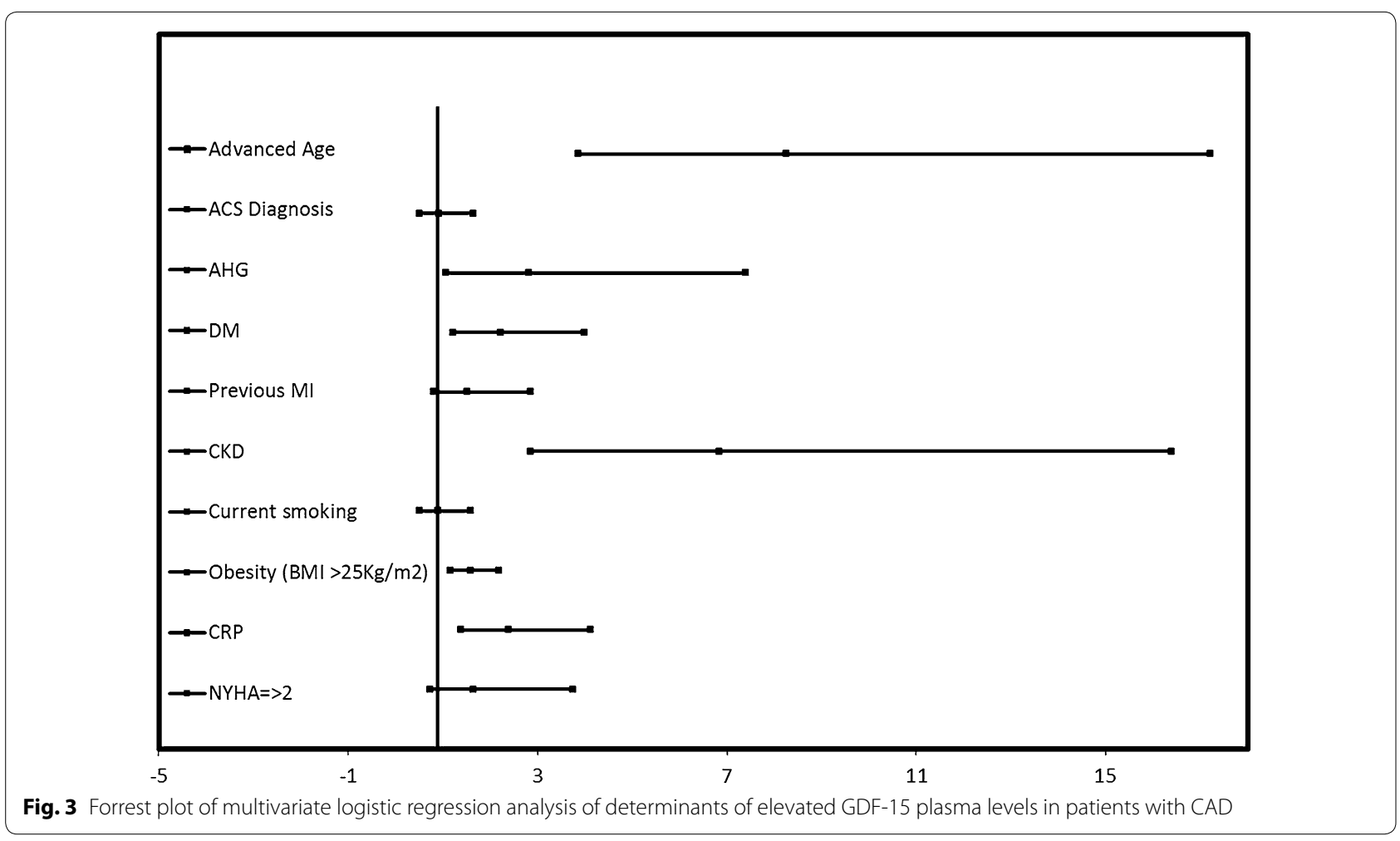

in patients with high risk NSTEMI [5]. In patients with STEMI a recent sub-study of the PLATO trial showed predictive impact of admission GDF-15 for future spontaneous MI and death [32]. A further analysis of the PLATO trial evidenced a predictive role for GDF-15 in patients with ASC undergoing, but not in those without invasive management [33]. Similarly in STEMI patients who underwent medical reperfusion therapy, GDF-15 levels were predictive of worse prognosis [2]. Wollert et al. found in a sub-investigation of the GUSTO IV trial that GDF-15 was a strong predictor of composite endpoint of death and MI [6]. However in that study the predictive power for the combined endpoint was mainly driven by the endpoint death and not MI [6]. Similar to those investigations, we found GDF-15 measured before coronary intervention in patients with CAD in stable and acute setting is a powerful predictor for death. However, GDF-15 was proven not predictive of combined ischemic endpoints of (non-fatal MI, UA, unplanned revascularization, ST, TIA and stroke). The main differences occurred in our vs. previous investigations could be explained by the fact that we investigated CAD patients in chronic as well as acute setting undergoing revascularization via PCI (PCI performed in $100 \%$ of the study population) compared to earlier studies performed by Wollert and Kempf [2,6] In those investigations patients were treated with thrombolytics or in less frequency received

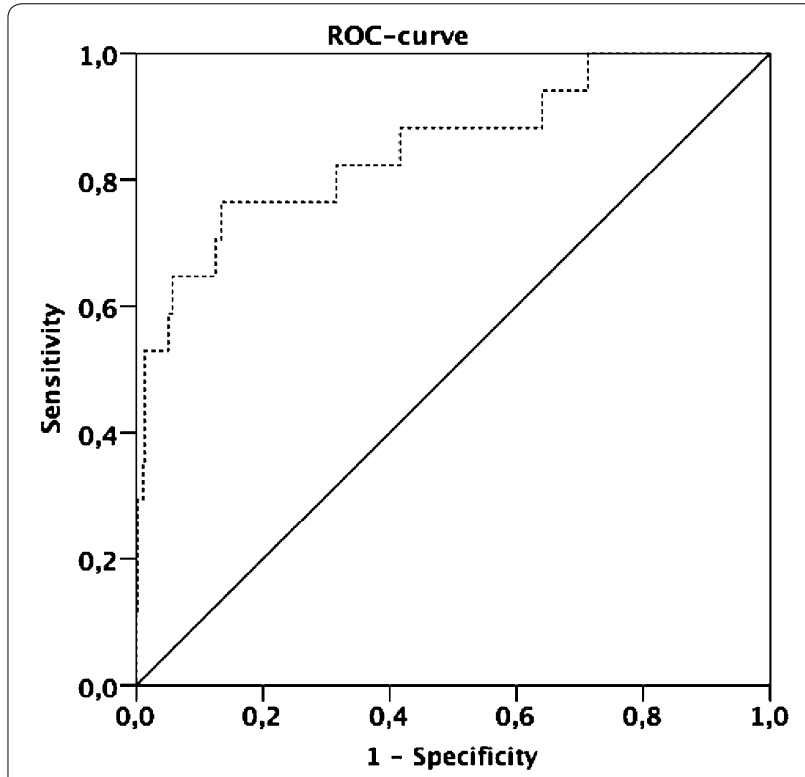

Fig. 4 Receiver operating curve (ROC) for GDF-15 and death during a mean follow-up of 188 (177.2-243) days (area under the curve (AUC) $0.852, \mathrm{Cl} 0.745-0.960, \mathrm{P}<0.0001)$

coronary intervention. Additionally the more recent studies from the PLATO investigators [32, 33] reflect more current guidelines and standard of care (in-hospital PCI and CABG $\sim 61$ and $4.5 \%$ respectively). 
Limitations our study has several limitations, which should be taken into account while interpreting the results. First, this is a single center investigation with a relative small sample size. Second, other than previous investigations we examined a mixed population of patients with proven CAD who needed a revascularization procedure via stent implantation. Therefore, our results should not be extrapolated to those patients treated medically, those who needed coronary artery bypass grafting as revascularization option and those with ACS treated medically only after evidencing no significant lumen narrowing of epicardial vessels in the coronary angiography. Finally, investigating the predictive value of a marker based on a single time point collection (snapshot) in a small patient population should be interpreted with caution and should be confirmed in further studies with higher sample size.

\section{Conclusion}

In patients with CAD undergoing PCI with stent implantation, GDF-15 is determined by advanced age, acute and chronic hyperglycemia, inflammation and chronic kidney disease. GDF-15 is a valuable predictor of CD-death in a population of CAD patients after PCI.

\section{Authors' contributions}

SF wrote manuscript, data analysis; MKF data entry and analysis; IB, data entry; VB data entry andpatient recruitment; BV data analysis and manuscript preparation; IT researched data; SBP laobratoryanalysis; KH edited mansucript and AKW edited mansucript. All authors read and approved the final manuscript.

\section{Authors' information \\ Serdar Farhan and loannis Tentzeris hold consultant for internal medicine positions, Matthias K. Freynhofer and Birgit Vogel work as residents at the department of Cardiology, Veronika Bruno worked as scientific researcher at the department of Cardiology and now she works as a resident at the department of obstetrics and gynecology at Wilhelminen hospital, Ivan Brozovic woks as a student researcher at the department of Cardiology, Sabina Baumgartner-Parzer is the head of the laboratory facility at the department of Endocrinology and Metabolism at the medical university of Vienna, Kurt Huber professor of Medicine and Cardiology is the head of the department of Cardiology at Wilhelminen hospital, Vienna and Alexandra Kautzky-Willer Professor of Medicine and head of the Gender Medicine Unit at the medical university of Vienna.}

\section{Author details}

1 3rd Department of Medicine, Cardiology, Wilhelminen Hospital, Montleartstrasse 37, A-1160 Vienna, Austria. ${ }^{2}$ Department of Obstetrics and Gynecology, Wilhelminen Hospital, Vienna, Austria. ${ }^{3}$ 3rd Department of Medicine, Division of Endocrinology and Metabolism, Medical University of Vienna, Vienna, Austria.

\section{Acknowledgements}

This manuscript is dedicated to the memory of Dr. Zoubir Farhan. This work was supported by the Association for the Promotion of Scientific Research in Arteriosclerosis, Thrombosis and Vascular Biology (ATVB). This manuscript has been supported by a Grant from the Österreichischer Herzfonds. We are grateful to Mrs. Ionasz Liliana-Imi from 3rd Department of Medicine, Division of Endocrinology and Metabolism, Medical University of Vienna, Vienna, Austria and Cand. Med. Spannbauer Andreas (Medical University of Vienna) for their kind help in performing the GDF-15 measurement and data entry.

\section{Competing interests}

The authors declare that they have no competing interests.

Received: 24 January 2016 Accepted: 24 March 2016

Published online: 08 April 2016

\section{References}

1. Bootcov MR, Bauskin AR, Valenzuela SM, Moore AG, Bansal M, He XY, Zhang HP, Donnellan M, Mahler S, Pryor K, et al. MIC-1, a novel macrophage inhibitory cytokine, is a divergent member of the TGF-beta superfamily. Proc Natl Acad Sci USA. 1997;94(21):11514-9.

2. Kempf T, Bjorklund E, Olofsson S, Lindahl B, Allhoff T, Peter T, Tongers J, Wollert KC, Wallentin L. Growth-differentiation factor-15 improves risk stratification in ST-segment elevation myocardial infarction. Eur Heart J. 2007;28(23):2858-65.

3. Hellemons ME, Mazagova M, Gansevoort RT, Henning RH, de Zeeuw D, Bakker SJ, Lambers-Heerspink HJ, Deelman LE. Growth-differentiation factor 15 predicts worsening of albuminuria in patients with type 2 diabetes. Diabetes Care. 2012;35(11):2340-6

4. Vila G, Riedl M, Anderwald C, Resl M, Handisurya A, Clodi M, Prager G, Ludvik B, Krebs M, Luger A. The relationship between insulin resistance and the cardiovascular biomarker growth differentiation factor-15 in obese patients. Clin Chem. 2011;57(2):309-16.

5. Damman P, KempfT, Windhausen F, van Straalen JP, Guba-Quint A, Fischer J, Tijssen JG, Wollert KC, de Winter RJ, Hirsch A. Growth-differentiation factor 15 for long-term prognostication in patients with non-ST-elevation acute coronary syndrome: an Invasive versus Conservative Treatment in Unstable coronary Syndromes (ICTUS) substudy. Int J Cardiol. 2014;172(2):356-63

6. Wollert KC, KempfT, Peter T, Olofsson S, James S, Johnston N, Lindahl B, Horn-Wichmann R, Brabant G, Simoons ML, et al. Prognostic value of growth-differentiation factor-15 in patients with non-ST-elevation acute coronary syndrome. Circulation. 2007;115(8):962-71.

7. Wollert KC, Kempf T, Lagerqvist B, Lindahl B, Olofsson S, Allhoff T, Peter T, Siegbahn A, Venge P, Drexler $\mathrm{H}$, et al. Growth differentiation factor 15 for risk stratification and selection of an invasive treatment strategy in non ST-elevation acute coronary syndrome. Circulation. 2007;116(14):1540-8.

8. Hong JH, Chung HK, Park HY, Joung KH, Lee JH, Jung JG, Kim KS, Kim HJ, Ku BJ, Shong M. GDF15 Is a Novel Biomarker for Impaired Fasting Glucose. Diabetes \& metabolism journal. 2014;38(6):472-9.

9. KempfT, Guba-Quint A, Torgerson J, Magnone MC, Haefliger C, Bobadilla M, Wollert KC. Growth differentiation factor 15 predicts future insulin resistance and impaired glucose control in obese nondiabetic individuals: results from the XENDOS trial. European journal of endocrinology/ European Federation of Endocrine Societies. 2012;167(5):671-8.

10. Freynhofer MK, Brozovic I, Bruno V, Farhan S, Vogel B, Jakl G, Willheim M, Hubl W, Wojta J, Huber K. Multiple electrode aggregometry and vasodilator stimulated phosphoprotein-phosphorylation assay in clinical routine for prediction of postprocedural major adverse cardiovascular events. Thromb Haemost. 2011;106(2):230-9.

11. Steg PG, James SK, Atar D, Badano LP, Blomstrom-Lundqvist C, Borger MA, Di Mario C, Dickstein K, Ducrocq G, Fernandez-Aviles F, et al. ESC Guidelines for the management of acute myocardial infarction in patients presenting with ST-segment elevation. Eur Heart J. 2012;33(20):2569-619.

12. Hamm CW, Bassand JP, Agewall S, Bax J, Boersma E, Bueno H, Caso P Dudek D, Gielen S, Huber K, et al. ESC Guidelines for the management of acute coronary syndromes in patients presenting without persistent ST-segment elevation: the Task Force for the management of acute coronary syndromes (ACS) in patients presenting without persistent STsegment elevation of the European Society of Cardiology (ESC). Eur Heart J. 2011;32(23):2999-3054.

13. Kosiborod M, Inzucchi SE, Krumholz HM, Masoudi FA, Goyal A, Xiao $L$, Jones PG, Fiske S, Spertus JA. Glucose normalization and outcomes in patients with acute myocardial infarction. Arch Intern Med. 2009;169(5):438-46.

14. K/DOQI clinical practice guidelines for chronic kidney disease. evaluation, classification, and stratification. American journal of kidney diseases: 
the official journal of the National Kidney Foundation. 2002;39(2 Suppl 1):S1-266.

15. McMurray JJ, Adamopoulos S, Anker SD, Auricchio A, Bohm M, Dickstein K, Falk V, Filippatos G, Fonseca C, Gomez-Sanchez MA, et al. ESC Guidelines for the diagnosis and treatment of acute and chronic heart failure 2012: the Task Force for the Diagnosis and Treatment of Acute and Chronic Heart Failure 2012 of the European Society of Cardiology. Developed in collaboration with the Heart Failure Association (HFA) of the ESC. Eur Heart J. 2012;33(14):1787-847.

16. Cutlip DE, Windecker S, Mehran R, Boam A, Cohen DJ, van Es GA, Steg PG, Morel MA, Mauri L, Vranckx P, et al. Clinical end points in coronary stent trials: a case for standardized definitions. Circulation. 2007;115(17):2344-51

17. Easton JD, Saver JL, Albers GW, Alberts MJ, Chaturvedi S, Feldmann E, Hatsukami TS, Higashida RT, Johnston SC, Kidwell CS, et al. Definition and evaluation of transient ischemic attack: a scientific statement for healthcare professionals from the American Heart Association/American Stroke Association Stroke Council; Council on Cardiovascular Surgery and Anesthesia; Council on Cardiovascular Radiology and Intervention; Council on Cardiovascular Nursing; and the Interdisciplinary Council on Peripheral Vascular Disease. The American Academy of Neurology affirms the value of this statement as an educational tool for neurologists. Stroke. 2009;40(6):2276-93.

18. Schlittenhardt D, Schober A, Strelau J, Bonaterra GA, Schmiedt W, Unsicker K, Metz J, Kinscherf R. Involvement of growth differentiation factor-15/macrophage inhibitory cytokine-1 (GDF-15/MIC-1) in oxLDLinduced apoptosis of human macrophages in vitro and in arteriosclerotic lesions. Cell Tissue Res. 2004;318(2):325-33.

19. KempfT, Eden M, Strelau J, Naguib M, Willenbockel C, Tongers J, Heineke J, Kotlarz D, Xu J, Molkentin JD, et al. The transforming growth factor-beta superfamily member growth-differentiation factor-15 protects the heart from ischemia/reperfusion injury. Circ Res. 2006;98(3):351-60.

20. Breit SN, Carrero JJ, Tsai VW, Yagoutifam N, Luo W, Kuffner T, Bauskin AR, Wu L, Jiang L, Barany P, et al. Macrophage inhibitory cytokine-1 (MIC-1/ GDF15) and mortality in end-stage renal disease. Nephrol Dial Transpl. 2012;27(1):70-5

21. Ho JE, Hwang SJ, Wollert KC, Larson MG, Cheng S, KempfT, Vasan RS, Januzzi JL, Wang TJ, Fox CS. Biomarkers of cardiovascular stress and incident chronic kidney disease. Clin Chem. 2013;59(11):1613-20.

22. Kahli A, Guenancia C, Zeller M, Grosjean S, Stamboul K, Rochette L, Girard C, Vergely C. Growth differentiation factor-15 (GDF-15) levels are associated with cardiac and renal injury in patients undergoing coronary artery bypass grafting with cardiopulmonary bypass. PLOS ONE. 2014;9(8):e105759.

23. Guenancia C, Kahli A, Laurent G, Hachet O, Malapert G, Grosjean S, Girard C, Vergely C, Bouchot O. Pre-operative growth differentiation factor 15 as a novel biomarker of acute kidney injury after cardiac bypass surgery. Int J Cardiol. 2015;197:66-71.
24. Dostalova I, Roubicek T, Bartlova M, Mraz M, Lacinova Z, Haluzikova D, Kavalkova P, Matoulek M, Kasalicky M, Haluzik M. Increased serum concentrations of macrophage inhibitory cytokine-1 in patients with obesity and type 2 diabetes mellitus: the influence of very low calorie diet. Eur J. Endocrinol. 2009;161(3):397-404.

25. Eggers KM, Kempf T, Wallentin L, Wollert KC, Lind L. Change in growth differentiation factor 15 concentrations over time independently predicts mortality in community-dwelling elderly individuals. Clin Chem. 2013;59(7):1091-8.

26. Ceriello A. Cardiovascular effects of acute hyperglycaemia: pathophysiological underpinnings. Diabetes Vasc Dis Res. 2008;5(4):260-8.

27. Knudsen EC, Seljeflot I, Abdelnoor M, Eritsland J, Mangschau A, Arnesen $\mathrm{H}$, Andersen GO. Abnormal glucose regulation in patients with acute ST-elevation myocardial infarction-a cohort study on 224 patients. Cardiovasc Diabetol. 2009;8:6.

28. Farhan S, Jarai R, Tentzeris I, Freynhofer MK, Brozovic I, Vogel B, KautzkyWiller A, Wascher T, Wojta J, Huber K. Admission proinsulin is associated with mortality in patients with admission hyperglycemia during acute coronary syndrome: results from a pilot observational study. Clin Chem. 2011;57(10):1456-60.

29. Kosiborod M, Rathore SS, Inzucchi SE, Masoudi FA, Wang Y, Havranek EP, Krumholz HM. Admission glucose and mortality in elderly patients hospitalized with acute myocardial infarction: implications for patients with and without recognized diabetes. Circulation. 2005;111(23):3078-86.

30. Baranyai T, Nagy CT, Koncsos G, Onodi Z, Karolyi-Szabo M, Makkos A, Varga ZV, Ferdinandy P, Giricz Z. Acute hyperglycemia abolishes cardioprotection by remote ischemic perconditioning. Cardiovasc Diabetol. 2015;14:151.

31. Li J, Yang L, Qin W, Zhang G, Yuan J, Wang F. Adaptive induction of growth differentiation factor 15 attenuates endothelial cell apoptosis in response to high glucose stimulus. PLOS ONE. 2013;8(6):e65549.

32. Velders MA, Wallentin L, Becker RC, van Boven AJ, Himmelmann A, Husted S, Katus HA, Lindholm D, Morais J, Siegbahn A, et al. Biomarkers for risk stratification of patients with ST-elevation myocardial infarction treated with primary percutaneous coronary intervention: insights from the platelet inhibition and patient outcomes trial. Am Heart J. 2015;169(6):879-89 e877.

33. Wallentin $L$, Lindholm D, Siegbahn A, Wernroth L, Becker RC, Cannon CP, Cornel JH, Himmelmann A, Giannitsis E, Harrington RA, et al. Biomarkers in relation to the effects of ticagrelor in comparison with clopidogrel in non-ST-elevation acute coronary syndrome patients managed with or without in-hospital revascularization: a substudy from the prospective randomized platelet inhibition and patient outcomes (PLATO) trial. Circulation. 2014;129(3):293-303.

\section{Submit your next manuscript to BioMed Central and we will help you at every step:}

- We accept pre-submission inquiries

- Our selector tool helps you to find the most relevant journal

- We provide round the clock customer support

- Convenient online submission

- Thorough peer review

- Inclusion in PubMed and all major indexing services

- Maximum visibility for your research

Submit your manuscript at www.biomedcentral.com/submit

\section{Biomed Central}

